\title{
Implementation of sequential design based water level monitoring and controlling system
}

\author{
Hussain Attia, Beza Getu, Abdullah Asaad, Ahmed Abbas, Mahmoud Al Nuaimi, Abdulhadi Brazi \\ Electrical, Electronics \& Communication Engineering Department, American University of Ras Al Khaimah, \\ Ras Al Khaimah, UAE
}

\begin{tabular}{l} 
Article Info \\
\hline Article history: \\
Received Jun 15, 2018 \\
Revised Oct 9, 2018 \\
Accepted Dec 8, 2018 \\
\hline
\end{tabular}

Keywords:

AC water pump

Drive circuit

J-K flip flop

Priority encoder

Sequential design

Water level sensor

\begin{abstract}
In currently decades, water usage either for domestic or commercial purposes is facing critical conditions which negatively affects the sustainability of our environment. From this point of view, reducing water consumptions will participate in the solution of water saving. Monitoring and controlling the tank water level are important functions which effect and work on reduction of water consumption. Many studies in literature focus on proposing a high performance water level monitoring and controlling systems based on either computerized units or microcontroller units. However these systems are characterized by complexity and high cost. In this paper, a highly flexible implemented electronic system is introduced based on sequential design by using general purpose discrete components. The proposed system present simple design of water level sensing stage, in addition, this paper showing full design, simulation, and implementation steps of an automation system which is able to control switching the state of the water pump in accordance to the current level of water in the tank.
\end{abstract}

Copyright $\odot 2019$ Institute of Advanced Engineering and Science. All rights reserved.

\section{Corresponding Author:}

Hussain Attia,

Electrical, Electronics \& Communication Engineering Department,

American University of Ras Al Khaimah,

Ras Al Khaimah, 10021, UAE.

Email: hattia@aurak.ac.ae

\section{INTRODUCTION}

The importance of water usage in different side of life like indoor (domestic) and outdoor (agriculture and industrial) that leads to increase the consideration of the leak of water sources and how reducing the water consuming in the water used activities. Many research studies were focused on objective of water management optimization through selecting a suitable lower cost sensing parts, efficient electronic design, and high performance implementation of the controlled pumping system.

The studies in [1]-[9], propose water level monitoring and water pump controlling based on different types of microcontroller units or computerized system with and without wireless remote monitoring ability, the proposed systems are characterized by high performance and accuracy, however, in the same time have demerit of complexity and high cost. Other studies [10]-[21] adopts electronics discrete components based for different sensing and controlling functions systems, while and the work in [21] proposed water level monitoring and control system completely based on discrete components.

The study in [1] proposes an automate pumping system based on a certain microcontroller that for LED screen displaying of water level detection and pumping of storage system. The study introduced performance improvement to the existing system through calibration circuit as well as eliminates the risk of electrocution by replacing AC by DC power. Different specifications microcontroller based automated water level management system of a main tank based is proposed in [2]. SMS message which include water level 
information that can be send from the system, as well as the system ability to do buzzers activation that to warm user.

Programmable Logic Controller (PLC) type SIEMENS LOGO! 24RL is programed and implemented with RTX-MID-3V transceivers as well as electrical motor to control automatically water pump in [3]. LED-s connected to the PLC-s outputs to have visually signaling system for a low cost water level control wireless solution. In [4], fuzzy logic is adopted for water level control in the tank, the level is sensed through the principle of transistor switching. Water level information is received by microcontroller PIC 16 continuously and sends back through serial communication to the user PC through serial communication COM port. The fuzzy logic is designed to control the water level according to the set point which set by the user.

National Instruments Lab VIEW software is used in [5] to have a highly powerful water level monitoring and controlling ability of large size buildings such as multistory buildings, and large public buildings. The proposed implemented system in [5] offers automatic switching ability of the pump on low water levels, information about water storage value as well as pump protection and under level or full tank alarming system. Supervisory Control And Data Acquisition (SCADA) with Human Machine Interface (HMI) were established and created respectively with help of Programmable Logic Controller (PLC) in [6] to propose an efficient supervised automated water level control system. Level data is provided to the PLC, the decisions of ON and OFF a water pump are done automatically based on the current level information. The controlling function is through SIMATIC S7-300 universal controller and reflects high quality performance of water level monitoring and controlling functions.

The study in [7], automated tank water level detection and controlling functions are done by using arduino microcontroller. The water pump switch ON or OFF is decided based on the currently water level, and level status is displayed on an LCD screen. The pump motor also protected from dry running in case the level of water is low inside the sump tank. The system also offers monitoring the level of water in the sump tank (source tank). An alarm beep sound signal is generated in case of low water level in the sump tank or in case any sensor faulting. The work in [8], proposes a designed, implemented, and tested of an Electric Water Pump Controller and Level Indicator (EWPCLI). The system monitors the presence of water through a certain type of water probes which produce digital outputs, these information enter microcontroller that to decide the suitable switching of the digital outputs to drive water pump. LED display is included in the system of [8] for visual merit to the system performance which characterized by eliminating the cost and eliminating of inefficiency of human interference. The study in [9], a water level sensing and controlled functions are done through a microcontroller based wired and wireless environment system. Water overflow and home power consumption is achieved through the proposed Water Level management system. Furthermore, the system can serve remote water monitoring that to support Global Water issue through cellular data loggers, satellite data transmission systems.

General purpose discrete components based systems are adopted for different objectives as shown in [10]-[20]. By the same methodology of discrete components based systems, the study in [21] proposed a simple monitoring and control system, the aim of the work is implementation of a water level controller though a Multisim to automatically control the electric water pump by switching ON and OFF in the domestic application. Water level indicators circuit design is done to facilitate the controlling function to houses water storage level, however the proposed system sense for only two level of water and have a missing part between simulation and implemented parts, Different types of wire and/or wireless sensors are used in [22]-[24] for different purpose proposals.

This paper proposes a new sequential logic design, simulation and full implementation of a discrete components based of water level monitoring and control. The design is started by simple sensor stage, with 8-water level feedback indications, the system is characterized by high performance, accuracy, simplicity due dependence on general purpose discrete components. The remaining of the paper is as follow; electronic design of the proposed system is explained in Section 2, simulation results are shown in Section 3 that to prove the correctness and accuracy of the electronic design. The illustration of the implemented system parts is done in Section 4, summary of conclusion is found out in Section 5.

\section{PROPOSED WATER LEVEL MONITORING AND CONTROLLING SYSTEM}

The proposed system includes six steps, namely; Sensor array, priority encoder, sequential design, drive circuit, 7-seqments decoder, and one digit display as shown in Figure 1 which represents the block diagram of the implemented water level monitoring and pump controlling system. 


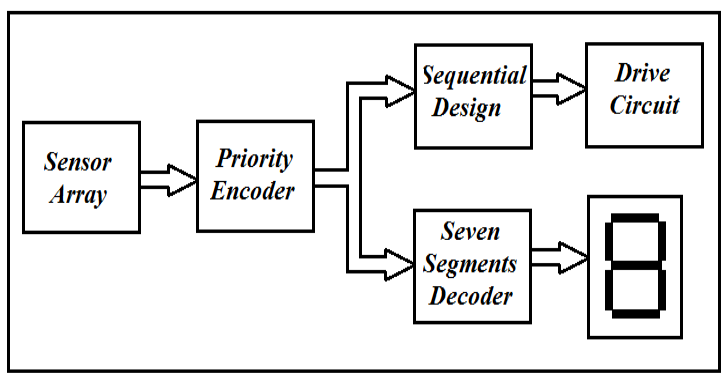

Figure 1. Block diagram of the proposed water level monitoring and controlling system

The design of the first stage of sensor array took in account the resistance of water which in the range of $50 \mathrm{k} \Omega$ to $100 \mathrm{k} \Omega$ (the selected simulated water resistance equals to $56 \mathrm{k} \Omega$ ) so by selecting a suitable voltage divider for each desired water level, the analog voltage which will enters the priority encoder that will be one of two levels. These two levels will be recognized as low and high levels by the priority encoder. To acquire the appropriate voltage value, $560 \mathrm{k} \Omega$ are connected to priority encoder inputs in series with the water resistor $56 \mathrm{k} \Omega$, the analog voltage levels will be $5 \mathrm{~V}$ in case there is no water connection or will be equal to the voltage value as illustrated below;

$$
\mathrm{V}_{\mathrm{R}}=5 \mathrm{~V} \times \frac{56 \mathrm{k}}{560 \mathrm{k}+56 \mathrm{k}}=0.455 \mathrm{~V}
$$

When the wires are not in contact with water, only $560 \mathrm{k} \Omega$ resistors are connected to inputs, and the voltages given are almost $5 \mathrm{~V}$ (logic 1$)$, when the water touches the wires, the resulted $0.455 \mathrm{~V}(\operatorname{logic} 0)$. Based on the two instantaneous values of digital inputs of the priority encoder, the encoder outputs will change. The priority encoder operates by choosing the highest priority of two inputs that are both the same; furthermore, the input with higher priority will take precedence [2]. The implemented encoder is an $8 \times 3$ priority encoder which used to transfer 8 inputs into 3 outputs, the selected priority encoder integrate circuit type is IC74148. For an encoder case example; if the inputs D7D6D5D4D3D2D1D0 are 11100000 (active low) the outputs A2A1A0 will give 011 (active low). By using the invertor, 100 is given to the BCD-to-seven segment decoder and number 4 is shown on the seven segment display.

Sequential design is adopted to manipulate the current state of water level, the design took in account that;

a) Water pump should be switching $\mathrm{ON}$ in case the water at level 1 or lower than level 1 (empty tank state).

b) Water pump should be switching OFF in case the water at level 7 or more than level 7 (Full tank state).

Water pump will be continuous switching $\mathrm{ON}$ at any water level in case it starts working from water level 1 and will be continuous ON till reaching level 7. Water pump will be continuous switching OFF at any water level in case it stops working from water level 7 and will be continuous OFF till reaching level 1.

Based on the above mentioned requirements as well as considering of JK flip flop truth table for the present and next state; the detailed truth table of the desired sequential design that is illustrated in the Table 1.

Table 1. Detailed Truth Table of the Desired Sequential Design

\begin{tabular}{cccccccc}
\hline Levels & A2 & A1 & A0 & Qn & Qn+1 & J & K \\
\hline 0 & 0 & 0 & 0 & 0 & 1 & 1 & $\mathrm{X}$ \\
0 & 0 & 0 & 0 & 1 & 1 & $\mathrm{X}$ & 0 \\
1 & 0 & 0 & 1 & 0 & 1 & 1 & $\mathrm{X}$ \\
1 & 0 & 0 & 1 & 1 & 1 & $\mathrm{X}$ & 0 \\
2 & 0 & 1 & 0 & 0 & 0 & 0 & $\mathrm{X}$ \\
2 & 0 & 1 & 0 & 1 & 1 & $\mathrm{X}$ & 0 \\
3 & 0 & 1 & 1 & 0 & 0 & 0 & $\mathrm{X}$ \\
3 & 0 & 1 & 1 & 1 & 1 & $\mathrm{X}$ & 0 \\
4 & 1 & 0 & 0 & 0 & 0 & 0 & $\mathrm{X}$ \\
4 & 1 & 0 & 0 & 1 & 1 & $\mathrm{X}$ & 0 \\
5 & 1 & 0 & 1 & 0 & 0 & 0 & $\mathrm{X}$ \\
5 & 1 & 0 & 1 & 1 & 1 & $\mathrm{X}$ & 0 \\
6 & 1 & 1 & 0 & 0 & 0 & 0 & $\mathrm{X}$ \\
6 & 1 & 1 & 0 & 1 & 1 & $\mathrm{X}$ & 0 \\
7 & 1 & 1 & 1 & 0 & 0 & 0 & $\mathrm{X}$ \\
7 & 1 & 1 & 1 & 1 & 0 & $\mathrm{X}$ & 1 \\
\hline
\end{tabular}

Implementation of sequential design based water level monitoring and controlling system (Hussain Attia) 
To define both $\mathrm{J}$ and $\mathrm{K}$ inputs of flip flop, $\mathrm{K}$ - maps are needed to simplify the logic expressions as shown below in Figure 2;

\begin{tabular}{|c|c|c|c|c|}
\hline \multicolumn{5}{|c}{$\mathrm{J}=\overline{A_{2}} \overline{A_{1}}=\overline{A_{2}+A_{1}}$} \\
\hline$A_{2} \bar{A}_{1} Q_{n}$ & $\overline{A_{0}} \overline{Q_{n}}$ & $\overline{A_{0}} Q_{n}$ & $A_{0} Q_{n}$ & $A_{0} \overline{Q_{n}}$ \\
\hline$\overline{A_{2}} \overline{A_{1}}$ & {$[1$} & $\mathrm{x}$ & $\mathrm{x}$ & $\underline{1}$ \\
\hline$\overline{A_{2}} A_{1}$ & 0 & $\mathrm{x}$ & $\mathrm{x}$ & 0 \\
\hline$A_{2} A_{1}$ & 0 & $\mathrm{x}$ & $\mathrm{x}$ & 0 \\
\hline$A_{2} \overline{A_{1}}$ & 0 & $\mathrm{x}$ & $\mathrm{x}$ & 0 \\
\hline
\end{tabular}

\begin{tabular}{|c|c|c|c|c|}
\hline \multicolumn{1}{|c|}{$\mathrm{K}=A_{2} A_{1} A_{0}$} \\
\hline$A_{2} \bar{A}_{1} Q_{n}$ & $\overline{A_{0}} \overline{Q_{n}}$ & $\overline{A_{0}} Q_{n}$ & $A_{0} Q_{n}$ & $A_{0} \overline{Q_{n}}$ \\
\hline$\overline{A_{2}} \overline{A_{1}}$ & $\mathrm{x}$ & 0 & 0 & $\mathrm{x}$ \\
\hline$\overline{A_{2}} A_{1}$ & $\mathrm{x}$ & 0 & 0 & $\mathrm{x}$ \\
\hline$A_{2} A_{1}$ & $\mathrm{x}$ & 0 & $\overline{1}$ & $\mathrm{x}$ \\
\hline$A_{2} \overline{A_{1}}$ & $\mathrm{x}$ & 0 & 0 & $\mathrm{x}$ \\
\hline
\end{tabular}

Figure 2. K-map of the J, K inputs of JK flip flop for the desired sequential design

From K- map, the simplified logic expressions of the JK flip flop inputs that are as follow;

$$
\begin{aligned}
& \mathrm{J}=\mathrm{A} 1 \text { NOR A2 } \\
& \mathrm{K}=\mathrm{A} 0 \text { AND A1 AND A2 }
\end{aligned}
$$

\section{SIMULATION AND IMPLEMENTATION OF PROPOSED SYSTEM}

The block diagram of Figure 1 which represents the proposed water level monitoring and AC pump control is simulated by National Instrument Multisim software of electronic circuits design; Figure 2 shows the full simulation of the proposed system;

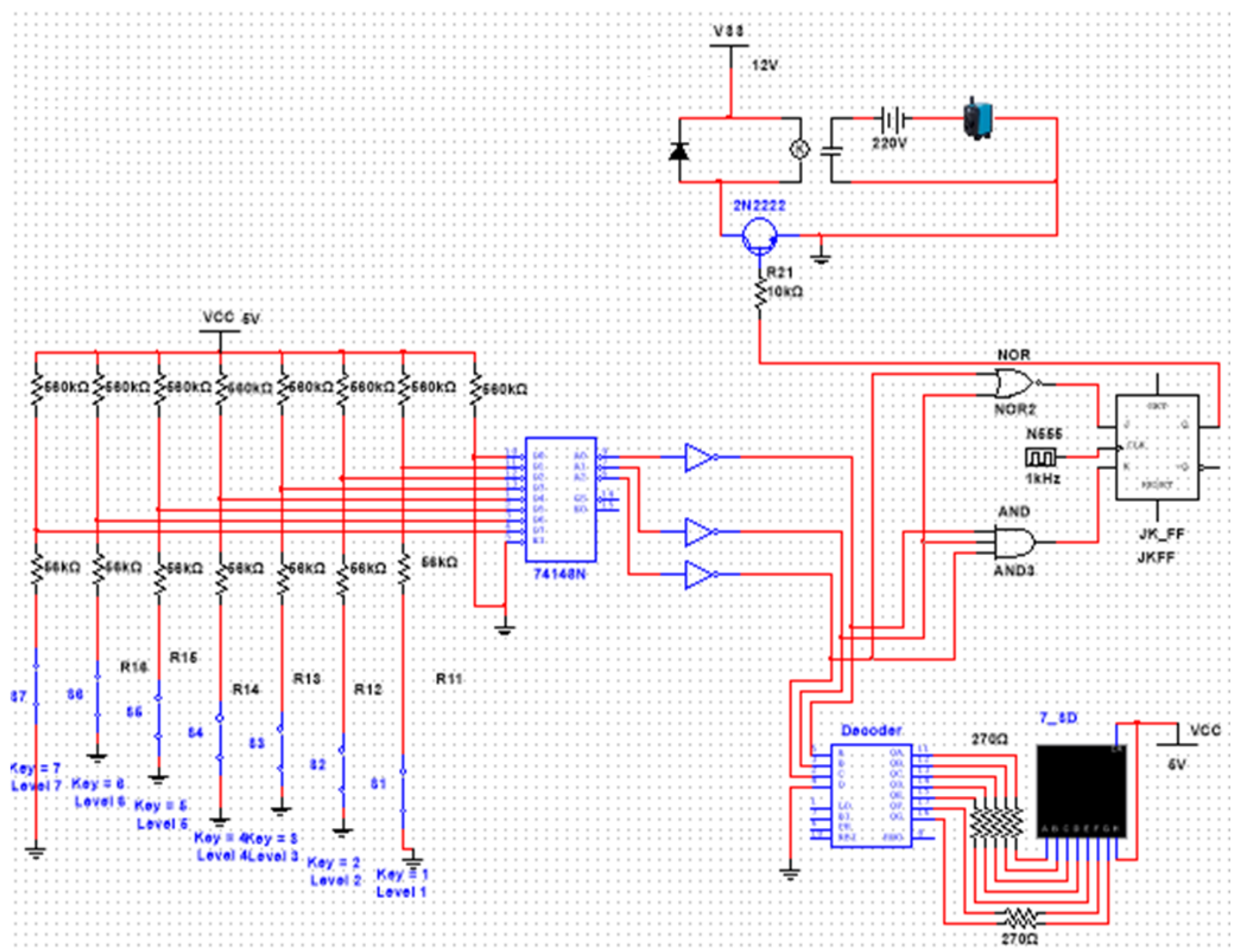

Figure 2. Simulation of the proposed system 


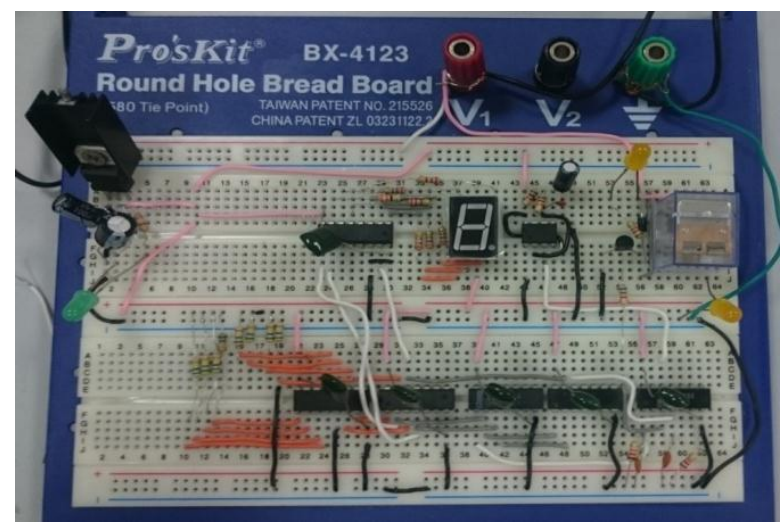

Figure 3. The experimentally implemented system

Figure 2 shows full simulation of the proposed system which includes all stages of the block diagram, first stage is sensor array which delivers information of water level through 8 -inputs of the priority encoder. Because the output terminals of the priority encoder are active low, a set of 3 - inverters are added to have active high logics, these logics are used as logic inputs to the 7-segments decoder to demonstrate the level of water through a 7-segments digit. On the other side, the 3-active high logics are enter to the JK flip flops through the logic combinations of 2-inputs NOR gate and 3-inputs AND gates based on the logic design. the Q output of JK flip flop is used to trigger the drive circuit that to switch the DC $12 \mathrm{~V}$ relay which is drive the AC pump. Figure 3 shows the experimentally implemented system which includes different TTL logic integrate circuits as well as the relay drive circuit. Figure 4 shows the power part of the system as well as the sample of experimentally tank. Figure 4 shown that the simplicity of the sensor array design which is done by only set of wires one for each water level in addition to other wire used to connect the ground terminal to the base of tank. The AC pump is connected to the AC $230 \mathrm{~V}$ supply through the Normally Open (NO) relay contacts that to control the switching of the pump.

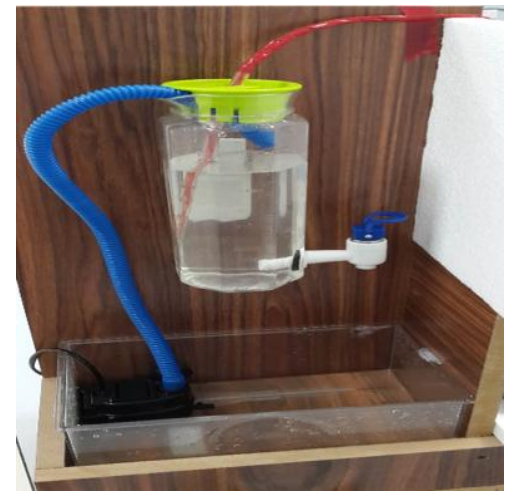

Figure 4. Power part of the system

\section{CONCLUSION}

In this paper, a design, simulation and implementation of water level monitoring and AC pump controlling is done based on sequential logic design by using general purpose discrete components. The presented system is characterized by highly flexibility and simplicity compared to the microcontroller units based systems. The presented system includes a very low cost sensor array because it was done by only using parallel wires one for each water level sensing. Using other types of sensor types such as the capacitance or the ultrasonic could give more accurate reading by using only one sensor in each tank since they work alongside the microprocessor, but the cost of these types is relatively high especially for home users. The presented system, besides water pump controlling offers reading out the instantaneous water level through a suitable size 7- segment display. The presented prototype of water level monitoring and control due its specifications of simplicity and flexibility reflects an effective implemented design of the promising system for home or industrial applications.

Implementation of sequential design based water level monitoring and controlling system (Hussain Attia) 


\section{ACKNOWLEDGEMENTS}

The authors appreciate the financial support provided by school of engineering, American University of Ras Al Khaimah - UAE, www.aurak.ac.ae/en/school-of-engineering/

\section{REFERENCES}

[1] Ejiofor Virginia Ebere, Oladipo Onaolapo Francisca, "Microcontroller based Automatic Water level Control System," International Journal of Innovative Research in Computer and Communication Engineering, Vol. 1, Issue 6, 2013, pp. 1390-1396.

[2] Poh-Kiong Teo, Chee-Chiang Derrick Tiew, “Automated Water Level Management System," International Journal of Computer and Electronics Research, Volume 4, Issue 1, 2015, pp. 11-16.

[3] Cosmina Illes, Gabriel Nicolae Popa and Ioan Filip, "Water level control system using PLC and wireless sensors," Conference Paper, DOI: 10.1109/ICCCyb.2013.6617587, 2013, https://www.researchgate.net/publication/261381165.

[4] Namrata Dey, Ria Mandal, M Monica Subashini, "Design and Implementation of a Water Level Controller using Fuzzy Logic,” International Journal of Engineering and Technology (IJET), Vol. 5, No. 3, 2013, pp. 2277-2285.

[5] Rajat Thakral, S. Chatterji, Shimi S.L, "A Novel Water Level Monitoring and Control of a Large Building Using NI LabVIEW," International Journal of Emerging Technology and Advanced Engineering, Vol. 2, Issue 7, 2012, pp. 100-104.

[6] Rishabh Das, Sayantan Dutta, Anusree Sarkar, Kaushik Samanta, "Automation of Tank Level Using Plc and Establishment of Hmi by Scada," IOSR Journal of Electrical and Electronics Engineering (IOSR-JEEE), Vol. 7, Issue 2, 2013, pp. 61-67.

[7] Asaad Ahmed Mohammedahmed Eltaieb, Zhang Jian Min, “Automatic Water Level Control System,” International Journal of Science and Research (IJSR), Vol. 4 Issue 12, 2015, pp. 1506-1509.

[8] Oghogho Ikponmwosa, and Azubuike Charles, "Development of an Electric Water Pump Controller and Level Indicator," International Journal of Engineering and Applied Sciences, Vol. 3, No. 2, 2013, pp. 18-21.

[9] S. M. Khaled Reza, Shah Ahsanuzzaman Md. Tariq, S.M. Mohsin Reza, "Microcontroller Based Automated Water Level Sensing and Controlling: Design and Implementation Issue," Proceedings of the World Congress on Engineering and Computer Science (WCECS 2010), San Francisco, USA.

[10] HA Attia, and BN Getu, "Design and Simulation of a Solar Tracking System for Optimum Energy Absorption," Int. J. of Thermal \& Environmental Engineering, Volume 8, Issue 1, 2014, pp. 17-24.

[11] HA Attia, YI Al-Mashhadany, and BN Getu,"Design and Simulation of a High Performance Standalone Photovoltaic System," - ICREGA'14-Renewable Energy: Generation and Applications, 2014, Publisher: Springer International Publishing, pp. 683-697.

[12] HA Attia, BN Getu, H Ghadban, and AKA Mustafa, "Portable Solar Charger with Controlled Charging Current for Mobile Phone Devices," Int. J. of Thermal \& Environmental Engineering, Volume 7, Issue 1, 2014, pp. 17-24.

[13] H Attia, B Getu, and Y Al-Mashhadany, "Design and Simulation of Dual Axis Solar Tracker for Optimum Solar Energy Absorption," The International Conference on Electrical and Electronics Engineering, Clean Energy and Green Computing (EEECEGC2013), Publisher: The Society of Digital Information and Wireless Communication, pp. 144-150.

[14] YI Al-Mashhadany, and HA Attia, "Novel Design and Implementation of Portable Charger through Low-Power PV Energy System,” Advanced Materials Research, Volume 925, 2014, pp. 495-499.

[15] HA Attia, BN Getu, and NA Hamad, “A Stable DC Power Supply for Photovoltaic Systems,” Int. J. of Thermal \& Environmental Engineering, Volume 12, Issue 1, 2016, pp.67-71.

[16] YI Al-Mashhadany, and HA Attia, "High performance for real portable charger through low power PV system," International Journal of Sustainable and Green Energy, Volume 4, Issue 3-1, 2015, pp. 14-18.

[17] Beza Negash Getu and Hussain A. Attia, "Remote Controlling of Light intensity Using Phone Devices," Research Journal of Applied Science, Engineering and Technology, Vol. 10, No. 10, 2015, pp. 1206-1215.

[18] Hussain A. Attia, Beza Negash Getu, "Design and Simulation of Remotely Power Controller," International Journal of Applied Engineering Research, Vol. 10, No. 12, 2015, pp. 32609-32626.

[19] Hussain A. Attia, "Three Steps AC Voltage Regulator Based on One Step-down Transformer," International Journal of Applied Engineering Research, Vol. 10, No. 19, pp 39898-39902, 2015.

[20] Hussain A. Attia, "A Binary Weighted 7-steps Automatic Voltage Regulator," Research Journal of Applied Sciences, Engineering and Technology, Vol.12, No. 9, pp. 947-954, 2016.

[21] Raghavendra.R, M.Uttara Kumari, S.A.Hariprasad, "Implementation of Simulated Water Level Controller," International Journal of Advanced Research in Computer Science and Software Engineering, Vol. 3, Issue 11, pp. 328-332, November 2013.

[22] Alaa A. Jaber, Robert B., "Design of a Wireless Sensor Node for Vibration Monitoring of Industrial Machinery," International Journal of Electrical and Computer Engineering (IJECE), Vol. 6, No. 2, April 2016, pp. 639-653.

[23] Amine B., Zakarya A., Abdelrhani N., "New Electromagnetic Force-Displacement Sensor," International Journal of Electrical and Computer Engineering (IJECE), Vol. 6, No. 2, April 2016, pp. 560-566.

[24] R.S. Uppal, Shakti K., "Big Bang-Big Crunch Algorithm for Dynamic Deployment of Wireless Sensor Network," International Journal of Electrical and Computer Engineering (IJECE), Vol. 6, No. 2, April 2016, pp. 596-601. 